\title{
Commentary
}

\section{Reporting Grantee Demographics for Diversity, Equity, and Inclusion in Neuroscience}

\author{
Suparna Choudhury ${ }^{1}$ and Neil K. Aggarwal ${ }^{2}$ \\ ${ }^{1}$ Division of Social and Transcultural Psychiatry, McGill University, Montreal, Quebec H3A 0G4, Canada, and ${ }^{2}$ New York State Psychiatric Institute \\ and Columbia University Medical Centre, New York, New York 10032
}

Professional neuroscience organizations have recently pledged their commitments to diversity, equity, and inclusion in examining institutional discrimination; to raise questions about how to train underrepresented scientists; and to recruit underrepresented subjects for a more equitable scientific enterprise in the 21st century. Studies have illuminated racial disparities in funding, likely because of implicit bias in the review process and differential access to resources. We propose that one concrete way to monitor and redress these disparities is to collect and publicize data on grantees by gender, race, ethnicity, and location from neuroscience funding agencies. Beyond remedying historical disadvantages, disseminating funding more equitably across recipients would be an empirical solution that can improve the very quality of neuroscience.

Key words: diversity; equity; funding; inclusion; racism research community

Professional neuroscience organizations have recently pledged their commitments to diversity, equity, and inclusion in examining institutional discrimination. The British Neuroscience Association has promoted the \#BlackInNeuroWeek initiative (July 27 to August 2, 2020) to celebrate Black voices in science, technology, engineering, and math (STEM) (https://www.bna. org.uk/mediacentre/news/blackinneuroweek/). The Federation of European Neuroscience Societies (FENS) has waived fees for scientists from low- and middle-income countries to attend its 2020 Virtual Forum (https://www.fens.org/News-Activities/ News/2020/07/FENS-2020-Diversity-grant-awardees/). The Society for Neuroscience has restated its plan to ensure diversity in its committees and membership (https://www.sfn.org/about/ mission-and-strategic-plan\#diversity). And Nature Neuroscience is determined to make manuscript review and citation more inclusive of gender (Nature Neuroscience, 2020) after investigators found that reference lists from five influential neuroscience journals included more articles with men as first and last authors (Dworkin et al., 2020).

These developments may prompt questions into why diversity, equity, and inclusion are necessary. To start, policymakers have found that education and employment rates for women and minorities lag behind their representation in the general population (Nature Neuroscience, 2018; National Science Foundation, 2019). At the same time, they constitute a growing part of the STEM workforce-minorities alone will constitute $45 \%$ of the American population by 2050 - and propel innovation by pursuing research agendas that have been historically

\footnotetext{
Received Aug. 31, 2020; accepted Sep. 2, 2020.

Author contributions: S.C. and N.K.A. performed research; S.C. and N.K.A. wrote the paper.

S.C. was supported by the Fonds de la recherche en santé du Québec (FRQS).

The authors declare no competing financial interests.

Correspondence should be addressed to Suparna Choudhury at suparna.choudhury@mcgill.ca

https://doi.org/10.1523/JNEUROSCI.2285-20.2020

Copyright $\odot 2020$ the authors
}

overlooked (National Academy of Sciences et al., 2011). Moreover, most basic science and clinical research studies enroll samples of convenience drawn from Western, educated, industrialized, rich, and democratic ("WEIRD") societies, and findings from American and European subjects may not be generalizable to populations elsewhere (Henrich et al., 2010). This raises a critical question: how do we train underrepresented scientists and recruit underrepresented subjects for a more equitable scientific enterprise in the 21 st century?

One way could be to collect and publicize data on grantees by gender, race, ethnicity, and location from organizations that allocate grants for neuroscience research. The ability to win large awards such as R01-level grants from the US National Institutes of Health (NIH) marks a milestone in career independence for neuroscientists (United States Government Accountability Office, 2018). But studies have illuminated disparities in funding. A 2011 study revealed that Black applicants were 10\% less likely than Whites to be awarded large NIH research grants from 2000 to 2006 after controlling for educational background, country of origin, training, previous research awards, publication record, and employer characteristics (Ginther et al., 2011). These differences were attributed to implicit biases in grant review and differential access to resources, mentorship, and training programs for minority neuroscientists.

A decade later, disparities in grant funding have persisted. The United States Government Accountability Office (GAO) found that a combined $17 \%$ of Black, Native American, and native Hawaiian applicants received large NIH grants from 2013 to 2017 , compared with $24 \%$ for Hispanic/Latinos, 24\% for Asians, and $27 \%$ for Whites; women comprised one-fourth of NIH tenured investigators despite completing half of all doctorates in the biological sciences (United States Government Accountability Office, 2018). In 2016, the NIH Office of Scientific Workforce Diversity outlined a 5 year plan to expand, sustain, and promote workforce diversity and build evidence on outcomes, but the GAO warned that the NIH would not hold itself accountable without quantitative 
metrics or time frames to assess its performance (United States Government Accountability Office, 2018).

As societies around the world seek to redress various forms of implicit bias and explicit discrimination against women and underrepresented minorities, now is the time to publicize information on grantee recipients by gender, race, ethnicity, and location. Reporting demographic data of applicants and grantees for major award schemes in neuroscience would be an empirical solution to monitoring disparities in funding. The NIH already does this for subjects of funded studies (https://report.nih.gov/RISR/\#/), suggesting that a similar model for grantees could be possible.

But beyond remedying historical disadvantages, this solution can improve the very quality of neuroscience. Disseminating funding across recipients who vary widely by gender, race, ethnicity, and geographic location could allow us to study the brain in the context of its social milieu, and to experimentally investigate mental processes as inherently social (Rose, 2016). Sharing data and paradigms across a wider international research community would help to generate and test hypotheses on the role of environmental, cultural, and socioeconomic factors in mechanisms of brain development across the lifespan and in the trajectory of mental disorders. Funding agencies could collect relevant demographic information and harness infrastructures from open neuroscience platforms to collect international data from ongoing projects and track the flow of resources. As a community committed to bringing transparency to the scientific process for "tangible activism" (Bumpus, 2020), neuro- scientists have much to gain from reporting and monitoring grantee demographics.

\section{References}

Bumpus N (2020) Too many senior white academics still resist recognizing racism. Nature 583:661.

Dworkin JD, Linn KA, Teich EG, Zurn P, Shinohara RT, Bassett DS (2020) The extent and drivers of gender imbalance in neuroscience reference lists. Nat Neurosci 23:918-926.

Ginther DK, Schaffer WT, Schnell J, Masimore B, Liu F, Haak LL, Kington R (2011) Race, ethnicity, and NIH research awards. Science 333:1015-1019.

Henrich J, Heine SJ, Norenzayan A (2010) Most people are not WEIRD. Nature 466:29.

National Academy of Sciences, National Academy of Engineering, and Institute of Medicine (2011) Expanding underrepresented minority participation: America's science and technology talent at the crossroads. Washington, DC: National Academies.

National Science Foundation (2019) Women, minorities, and persons with disabilities in science and engineering. Alexandria, VA: National Science Foundation.

Nature Neuroscience (2018) Promoting diversity in neuroscience. Nat Neurosci 21:1.

Nature Neuroscience (2020) Widening the scope of diversity. Nat Neurosci 23:903.

Rose N (2016) Neuroscience and the future for mental health. Epidemiol Psychiatr Sci 25:95-100.

United States Government Accountability Office (2018) NIH research: action needed to ensure workforce diversity strategic goals are achieved. Washington, DC: United States Government Accountability Office. 